\title{
Cost-effectiveness of pneumococcal vaccination for prevention of invasive pneumococcal disease in the elderly: an update for 10 Western European countries
}

\author{
S. M. A. A. Evers - A. J. H. A. Ament - G. L. Colombo • \\ H. B. Konradsen • R. R. Reinert • D. Sauerland • \\ K. Wittrup-Jensen • C. Loiseau • D. S. Fedson
}

Published online: 15 June 2007

(C) Springer-Verlag 2007

\begin{abstract}
Pneumococcal vaccine is effective in preventing invasive pneumococcal disease in adults $\geq 65$ years of age, but it is not widely used in Western Europe. In this study, data from an earlier (1995) cost-effectiveness study on Belgium, France, Scotland, Spain, and Sweden are updated, and data on five new countries-Denmark, the UK (specifically, England and Wales), Germany, Italy and The Netherlands - are added. Epidemiological and economic variables specific for each country were used, and it was assumed that pneumococcal and influenza vaccines would both be administered during the same physician visit. In the base-case analyses, the cost-effectiveness ratios ranged from $€ 9239$ to $€ 23,657$ per quality-adjusted life-year. Because the incidence and mortality of invasive pneumococcal disease were underestimated in most countries, a country-by-country analysis was performed, assuming an incidence of 50 cases per 100,000 population and mortality
\end{abstract}

S. M. A. A. Evers $(\square) \cdot$ A. J. H. A. Ament

Department of Health, Organization, Policy and Economics,

Maastricht University, PO Box 616, Maastricht,

6200 MD, The Netherlands

e-mail: s.evers@BEOZ.unimaas.nl

G. L. Colombo

S.A.V.E. (Studi Analisi Valutazioni Economiche), Via Previati 74,

20149, Milan, Italy

H. B. Konradsen

Department of Bacteriology, Mycology and Parasitology,

Statens Serums Institute, Artillerivej 5,

2300, Copenhagen S, Denmark

\section{R. R. Reinert}

Institute of Medical Microbiology,

National Reference Centre for Streptococci,

University Hospital of Aachen, Pauwelstr. 30,

52 074, Aachen, Germany rates of 20,30 and $40 \%$. For a mortality of $20 \%$, the costeffectiveness ratios ranged from $€ 4,778$ to $€ 17,093$, and for a mortality of $30 \%$, they ranged from $€ 3,186$ to $€ 11,395$. Pneumococcal vaccination to prevent invasive pneumococcal disease in elderly adults was very cost-effective in all 10 countries. This evidence justifies the wider use of the vaccine in Western Europe.

\section{Introduction}

Pneumococcal infection causes considerable morbidity and mortality among elderly persons in developed countries [1]. Invasive or bacteremic pneumococcal disease (IPD) is the most serious manifestation, and hospital treatment for individual cases can be very costly. Prospective clinical trials in elderly persons and their meta-analyses have

\section{Sauerland}

Department of Economics,

WHL Graduate School of Business and Economics,

Hohbergweg 15-17,

77933, Lahr, Germany

\section{K. Wittrup-Jensen}

International Marketing, Pricing, and PharmacoEconomics,

Virum, Novo Nordisk A/S,

Hummeltoftevej 49,

2830, Virum, Denmark

C. Loiseau

Sanofi Pasteur MSD,

8 rue Jonas Salk,

69007, Lyon, France

D. S. Fedson

57 Chemin du Lavoir,

01630, Sergy Haut, France 
attempted to show that $14-$ and 23-valent pneumococcal polysaccharide vaccine prevents hospitalization of patients for pneumococcal pneumonia or all-cause pneumonia, but the results have been inconclusive [1, 2]. In contrast, several observational studies have shown that the aggregate effectiveness of pneumococcal vaccination is approximately 50 $70 \%$ in preventing hospitalization for IPD [1,3-9].

The use of pneumococcal vaccine has increased recently in some but not all developed countries $[1,10]$. This is due to better understanding of the clinical effectiveness of vaccination for elderly persons, but it also reflects better understanding of the cost-effectiveness of vaccination. The initial cost-effectiveness studies of pneumococcal vaccination focused on preventing pneumococcal pneumonia, but they were unpersuasive because there was no evidence that vaccination was clinically effective in preventing this outcome $[1,11]$. However, a study from the USA demonstrated that pneumococcal vaccination of persons 65 years of age and older would be cost-saving if it only prevented hospitalization for pneumococcal bacteremia [12]. Because of the difficulty in applying the conclusions from the U.S. study to other countries, we conducted a cross-national comparison for five Western European countries (Belgium, France, Scotland, Spain, and Sweden) [13]. Using a common model that incorporated epidemiological and economic variables from each country, we showed that pneumococcal vaccination to prevent invasive pneumococcal disease would be very cost-effective in each country.

Several observers continue to insist that if widespread use of pneumococcal vaccine is to be worthwhile, it must be effective in preventing pneumococcal pneumonia; in other words, nonbacteremic as well as bacteremic cases [14-19]. Moreover, several Western European countries still do not have recommendations for pneumococcal vaccination of elderly persons and use very little vaccine $[1,10]$. For these reasons, we decided to update our earlier cost-effectiveness study for the five original countries and add five new countries: three countries with large populations (England and Wales, Germany, and Italy) and two countries (Denmark and The Netherlands) for which good epidemiological data were available.

\section{Materials and methods}

\section{Model}

We determined the cost-effectiveness of pneumococcal vaccination in preventing hospitalization for invasive pneumococcal disease (IPD) for elderly persons 65 years of age and older in ten Western European countries. For five of these countries (Belgium, France, Scotland, Spain, and Sweden), we updated findings from our earlier 1995 cost-effectiveness study [13]. For five new countries (Denmark, England and Wales, Germany, Italy, and The Netherlands), we based our findings on country-specific epidemiological and economic data for 1 year. Because the clinical effectiveness and costeffectiveness of pneumococcal vaccination varies with age $[5,13,20]$, we performed separate analyses for persons 65 $74,75-84$, and 85 years of age and older, as well as for all persons 65 years of age and older. Full details on our model have been published previously [13].

We followed the principles of "reference case analysis" in our evaluation [21]. We used a cohort model instead of a more complex Markov model because transition probabilities from one state to another over short time periods, which are the basis of Markov modelling, are of little added value when looking at vaccination strategies for IPD [22, 23]. We considered two hypothetical cohorts: one that received pneumococcal vaccine and one that did not. Both cohorts were followed throughout their life spans. The life spans of individuals in the cohorts without vaccination were calculated on the basis of age-specific mortality rates (Population and mortality. In: European Communities, 1995-2002. Eurostat Data Shop, Health Statistics Netherlands, Voorburg, Netherlands, unpublished data). The life spans of those in the vaccinated cohorts were affected only during the period when vaccination was effective. The differences in life years between cohorts with and without vaccination were calculated for each age group for each year of life. Life years gained due to vaccination were corrected for quality of life $[13,24]$. This resulted in the number of quality-adjusted life-years (QALYs) gained by pneumococcal vaccination.

For each cohort, we calculated the differences in hospitalization costs for IPD for each age group and each year of life. The costs were a function of vaccination effectiveness, hospital admission rate, average length of stay (ALOS) and cost of one hospital day in each country. The costs per QALY gained by vaccination were expressed as cost-effectiveness ratios (CERs); i.e., the costs of achieving one additional QALY in the vaccinated cohort. The analyses reflected a societal point of view and all future costs and health effects were discounted at $3 \%[13,21]$.

Epidemiological variables

Data on the effectiveness of pneumococcal vaccination, the incidence and mortality of IPD, the age-specific mortality rates, and the age-specific differences in quality of life were incorporated into the model [13]. We used estimates of vaccination effectiveness that were obtained from an earlier case-control study [5]. These estimates were used in the earlier U.S. cost-effectiveness study [12], and we used them in our earlier study [13]. We did not include adverse events following vaccination in our analyses because they have very little effect on the cost-effectiveness ratios [12]. 
For 7 of the 10 countries we obtained data on the incidence of IPD from population-based studies. Cases were identified from hospital clinical microbiology laboratory reports. For each case, one or more isolates of Streptococcus pneumoniae had been obtained from a normally sterile extrapulmonary site (e.g., blood or cerebrospinal fluid) during a single hospital stay. (Table 1) [1, 13]. Some reports also included information on the outcome of hospital care (survival or death). For England and Wales, we used data on incidence and mortality derived from a published study [25]. For Germany we used data derived from a recently completed study [26]. At the time we conducted our analyses, there was no published information on the incidence and mortality of IPD in Italy, so we used estimates based on experience in the other nine countries. Details on the sources of the epidemiological variables are provided in our earlier publication [13] and in the Appendix.

\section{Economic variables}

Given the differences in healthcare systems, cost estimates varied from country to country (Table 2). We estimated costs in euros. Wherever data were available, we based our estimates on real costs (resources consumed) rather than on charges [27]. We considered only direct medical costs for vaccination and hospital care for IPD. We excluded outpatient care costs for IPD and future costs of medical care.

We obtained information on the retail price of the vaccine in each country (Aventis Pasteur MSD, unpublished data). In the base-case analyses, we assumed that pneumococcal and influenza vaccines would be administered during the same physician visit. Data from Spain and The Netherlands indicated that pneumococcal vaccination added to the administration of influenza vaccine incurred additional administration costs of $€ 2.59$ and $€ 4.02$, respectively (M. Postma, personal communication; the costs included those associated with prescribing and billing, but did not include labour costs for the injection). We set the additional cost for pneumococcal vaccine administration at $€ 3.00$ for all 10 countries.

We obtained information on the ALOS for IPD (or, if this was not available, for pneumonia) for each country. Because reimbursement systems are different in each country, we could not adopt a uniform approach to estimating the hospital costs for treating individual cases of IPD (Table 2). In countries where hospital care is financed according to diagnosis-related groups (DRGs), we used DRG reimbursements for these estimates. In some countries, we used reports of "special daily rates" for financing specific hospital departments (e.g., internal medicine). In other countries, where hospitals are financed through global budgets, we used the average national costs of a 1-day hospital stay. Where possible, our cost estimates reflected acute hospital care, including costs for specialist physicians, medications, and hospital overhead and investments. We did not consider days spent in intensive care units and we excluded inpatient costs for nonbacteremic pneumococcal pneumonia and long-term and psychiatric care. Details on how we obtained cost estimates for each country are provided in our earlier publication [13] and in the Appendix.

\section{Sensitivity analyses}

We conducted both univariate and two-way sensitivity analyses for all persons 65 years of age and older. In the univariate analyses, we considered the cost-effectiveness of administering pneumococcal vaccine by itself, increasing or

Table 1 Epidemiological data for invasive pneumococcal disease in the base-case analyses

Belgium $^{\mathrm{a}} \quad$ Denmark $^{\mathrm{b}} \quad$ England $\quad$ France $^{\mathrm{a}} \quad$ Germany $^{\mathrm{b}} \quad$ Italy $^{\mathrm{b}} \quad$ The Netherlands $^{\mathrm{b}} \quad$ Scotland $^{\mathrm{a}} \quad$ Spain $^{\mathrm{a}} \quad$ Sweden $^{\mathrm{a}}$
and Wales ${ }^{\mathrm{b}}$

\begin{tabular}{|c|c|c|c|c|c|c|c|c|c|c|}
\hline \multicolumn{11}{|c|}{ Incidence (per 100,000) } \\
\hline $65-74$ years & 28.3 & 50.0 & 23.0 & 20.5 & - & - & 42.0 & 21.8 & 40.0 & 22.7 \\
\hline $75-84$ years & 41.2 & 72.9 & 37.0 & 28.6 & - & - & 66.0 & 33.8 & 83.1 & 34.1 \\
\hline$\geq 85$ years & 65.4 & 99.3 & 95.0 & 67.7 & - & - & 92.1 & 62.9 & 74.5 & 49.2 \\
\hline$\geq 65$ years & 35.6 & 63.9 & 36.0 & 29.3 & $50.0^{\mathrm{c}}$ & $50.0^{\mathrm{c}}$ & 55.1 & 29.5 & 57.2 & 34.1 \\
\hline \multicolumn{11}{|l|}{ Mortality (\%) } \\
\hline $65-74$ years & $12.8^{\mathrm{d}}$ & 12.8 & 16.0 & 18.9 & - & - & $15.7^{\mathrm{d}}$ & $24.5^{\mathrm{d}}$ & $8.0^{\mathrm{d}}$ & 6.3 \\
\hline $75-84$ years & $19.9^{\mathrm{d}}$ & 31.4 & 20.0 & 20.6 & - & - & $16.9^{\mathrm{d}}$ & $40.0^{\mathrm{d}}$ & $22.7^{\mathrm{d}}$ & 12.9 \\
\hline$\geq 85$ years & $26.3^{\mathrm{d}}$ & 40.0 & 17.0 & 42.4 & - & - & $17.8^{\mathrm{d}}$ & $52.1^{\mathrm{d}}$ & $26.8^{\mathrm{d}}$ & 20.7 \\
\hline$\geq 65$ years & $19.3^{\mathrm{d}}$ & 22.8 & 18.0 & 25.8 & $20.0^{\mathrm{c}}$ & $20.0^{\mathrm{c}}$ & $16.6^{\mathrm{d}}$ & $37.9^{\mathrm{d}}$ & $17.6^{\mathrm{d}}$ & 11.7 \\
\hline
\end{tabular}

${ }^{\mathrm{a}}$ Reported earlier [13]

${ }^{\mathrm{b}}$ See Appendix for details

${ }^{\mathrm{c}}$ No data were available for the three age groups individually. Estimates were used for all persons $\geq 65$ years of age

${ }^{\mathrm{d}}$ In the absence of specific data for IPD, data for pneumonia (International Classification of Diseases, 9th version, 480-486) were used 
Table 2 Estimated costs for each country included in the study

\begin{tabular}{|c|c|c|c|c|c|c|c|c|c|c|}
\hline & Belgium $^{a}$ & Denmark $^{b}$ & $\begin{array}{l}\text { England } \\
\text { and Wales }\end{array}$ & France $^{\mathrm{a}}$ & Germany $^{\mathrm{b}}$ & Italy $^{\mathrm{b}}$ & Netherlands ${ }^{\mathrm{b}}$ & Scotland ${ }^{\mathrm{a}}$ & Spain $^{\mathrm{a}}$ & Sweden $^{\mathrm{a}}$ \\
\hline \multicolumn{11}{|l|}{ Vaccine-associated costs ${ }^{\mathrm{c}}$} \\
\hline $\begin{array}{l}\text { Vaccine price } \\
\text { Vaccine administration }\end{array}$ & 17.9 & 16.6 & 14.4 & 13.6 & 27.1 & 25.8 & 17.5 & 14.4 & 14.4 & 7.5 \\
\hline Base case $^{\mathrm{d}}$ & 3.0 & 3.0 & 3.0 & 3.0 & 3.0 & 3.0 & 3.0 & 3.0 & 3.0 & 3.0 \\
\hline Sensitivity analysis ${ }^{\mathrm{e}}$ & $16.2^{\mathrm{f}}$ & 12.6 & 22.6 & $21.5^{\mathrm{f}}$ & 18.8 & 7.0 & 17.1 & $18.9^{\mathrm{f}}$ & $16.4^{\mathrm{f}}$ & $12.9^{\mathrm{f}}$ \\
\hline \multicolumn{11}{|l|}{ Hospital-associated costs } \\
\hline $\begin{array}{l}\text { Hospital care } \\
\text { (per day) }\end{array}$ & $285^{\mathrm{f}}$ & 386 & 550 & $419^{\mathrm{f}}$ & 300 & 288 & 260 & $472^{\mathrm{f}}$ & $252^{\mathrm{f}}$ & $375^{\mathrm{f}}$ \\
\hline \multicolumn{11}{|l|}{ ALOS (days) } \\
\hline $65-74$ years & $16.5^{\mathrm{g}}$ & 11.9 & 14.0 & 14.4 & $15.1^{\mathrm{g}}$ & $13.1^{\mathrm{g}}$ & $12.0^{\mathrm{g}}$ & $5.4^{\mathrm{g}}$ & 11.6 & 11.0 \\
\hline $75-84$ years & $19.1^{\mathrm{g}}$ & 10.4 & 17.0 & 12.4 & $14.7^{\mathrm{g}, \mathrm{h}}$ & $16.0^{\mathrm{g}}$ & $18.5^{\mathrm{g}}$ & $7.6^{\mathrm{g}}$ & 12.1 & 9.9 \\
\hline$\geq 85$ years & $20.7^{\mathrm{g}}$ & 9.7 & 14.0 & 11.8 & $14.7^{\mathrm{g}, \mathrm{h}}$ & $15.4^{\mathrm{g}}$ & $27.9^{\mathrm{g}}$ & $9.4^{\mathrm{g}}$ & 9.8 & 10.7 \\
\hline$\geq 65$ years & $18.7^{\mathrm{g}}$ & 11.1 & 15.0 & 13.1 & $12.9^{\mathrm{g}}$ & $14.9^{\mathrm{g}}$ & $18.0^{\mathrm{g}}$ & $7.8^{\mathrm{g}}$ & 11.5 & 10.5 \\
\hline $\begin{array}{l}\text { Cost per hospital } \\
\text { admission } \geq 65 \text { years }^{\mathrm{c}}\end{array}$ & 5,324 & 4,286 & 8,360 & 5,484 & 3,870 & 4,296 & 4,673 & 3,681 & 2,903 & 3,942 \\
\hline
\end{tabular}

ALOS average length of stay

${ }^{\text {a }}$ Reported earlier [13]

${ }^{\mathrm{b}}$ See Appendix for details

${ }^{\mathrm{c}}$ For all countries, 1999 vaccine prices (in ) were used

${ }^{\mathrm{d}}$ The base-case analyses assumed that pneumococcal vaccine would be administered during the same visit as the influenza vaccine

${ }^{\mathrm{e}}$ The sensitivity analyses assumed that pneumococcal vaccine would be administered on a separate visit, not on the same visit as the influenza vaccine

${ }^{\mathrm{f}}$ The 1995 monetary data were discounted to 1999 figures using the medical price index

${ }^{\mathrm{g}}$ In the absence of specific data for IPD, data for all pneumonia (ICD-9 code 480-486, see Appendix) were used

${ }^{\mathrm{h}}$ Only figure provided for $75+$

lowering its price by $€ 3.00$, and increasing or lowering the clinical effectiveness of vaccination (the upper and lower bounds of the $95 \%$ confidence intervals of the point estimates we used) $[5,12,13]$. We also considered a range of estimates for the incidence ( $30-50$ per 100,000 persons) and mortality (20-40\%) of IPD because reported rates for these two variables differed substantially between the 10 countries [1, 13]. In addition, we examined the costeffectiveness of vaccination without adjusting for qualityof-life and by changing the discount rate $(0 \%$ and $5 \%)$. In the two-way sensitivity analyses, we used an incidence of 50 cases per 100,000 persons and mortality rates of $20 \%$, $30 \%$, or $40 \%$ for all 10 countries. All other variables in the two-way sensitivity analyses were those used in the base case [13].

\section{Updating the 1995 results}

In our earlier report for Belgium, France, Scotland, Spain, and Sweden, we reported cost-effectiveness results for the year 1995 [13]. We updated results for these countries to 1999 using the (medical) price index and 1999 vaccine prices. Age-specific population estimates and mortality rates also were updated to 1999 using Eurostat data.

\section{Results}

Base-case analyses

Table 3 shows the results of the base-case analyses for the three age groups and for all persons $\geq 65$ years of age. There was substantial variation in the cost-effectiveness ratios for individual countries; for persons $\geq 65$ years of age, they ranged from $€ 9,239$ for Denmark to $€ 23,657$ for Sweden. In the eight countries for which CERs for the three age groups could be calculated, the CERs generally increased for older age groups.

\section{Sensitivity analyses}

Table 4 shows the results of the sensitivity analyses performed for all persons $\geq 65$ years of age. In the univariate analyses, the CERs decreased substantially when the incidence and mortality rates for IPD increased (Germany and Italy excluded). The CERs were also sensitive to a change in vaccination strategy, increasing when pneumococcal vaccine was administered on a separate physician visit instead of on the same visit as the influenza vaccine. In addition, a lower level of vaccination effectiveness had a marked effect on the CERs. Compared with results in the 
Table 3 Results of the base-case analyses, expressed as cost-effectiveness ratios in euros (1999) per QALY gained (see text for details)

\begin{tabular}{|c|c|c|c|c|c|c|c|c|c|c|}
\hline Age group (years) & Belgium $^{\mathrm{a}}$ & Denmark $^{\mathrm{b}}$ & $\begin{array}{l}\text { England } \\
\text { and Wales }\end{array}$ & France $^{\mathrm{a}}$ & Germany $^{\mathrm{b}}$ & Italy $^{\mathrm{b}}$ & Netherlands ${ }^{\mathrm{b}}$ & Scotland $^{\mathrm{a}}$ & Spain $^{\mathrm{a}}$ & Sweden $^{\mathrm{a}}$ \\
\hline $65-74$ & 19,324 & 8,056 & 13,820 & 14,023 & $-^{\mathrm{c}}$ & $-^{\mathrm{c}}$ & 10,784 & 12,437 & 12,720 & 20,385 \\
\hline $75-84$ & 25,194 & 8,753 & 19,539 & 24,073 & $-^{\mathrm{c}}$ & $-^{\mathrm{c}}$ & 17,456 & 14,319 & 8,878 & 23,490 \\
\hline$\geq 85$ & 57,219 & 23,786 & 41,664 & 23,743 & $-^{\mathrm{c}}$ & $-^{\mathrm{c}}$ & 55,790 & 25,569 & 46,000 & 48,108 \\
\hline$\geq 65$ & 22,847 & 9,239 & 17,228 & 17,444 & 17,093 & 16,544 & 13,740 & 13,920 & 12,027 & 23,657 \\
\hline
\end{tabular}

${ }^{\mathrm{a}}$ Reported earlier [13]

${ }^{\mathrm{b}}$ See Appendix for details

${ }^{\mathrm{c}}$ Cost-effectiveness ratios could not be calculated for the age subgroups in these countries because data on the incidence of disease were not available

base-case analyses, the CERs were less affected by changes in the values for other variables (vaccine price, ALOS, no quality-of-life adjustment, and discount rate).

The two-way sensitivity analyses for all 10 countries assumed that the incidence of IPD was 50 cases per 100,000 elderly persons and the mortality rates were $20 \%, 30 \%$, or $40 \%$
(Table 4). For most countries, this led to substantial reductions in the CERs compared with the CERs obtained in the base-case analyses. Moreover, there was a striking narrowing of the CER differences between all countries. For example, when the mortality rate for IPD was $30 \%$, the CERs ranged from $€ 3,186$ in Sweden to $€ 11,395$ in Germany.

Table 4 Results of the sensitivity analyses for all persons $\geq 65$ years of age, expressed as cost-effectiveness ratios in euros (1999) per QALY gained. See text for details

\begin{tabular}{|c|c|c|c|c|c|c|c|c|c|c|}
\hline & Belgium $^{\mathrm{a}}$ & Denmark $^{\mathrm{b}}$ & $\begin{array}{l}\text { England } \\
\text { and Wales }\end{array}$ & France $^{\mathrm{a}}$ & Germany $^{\mathrm{b}}$ & Italy $^{\mathrm{b}}$ & Netherlands ${ }^{\mathrm{b}}$ & Scotland $^{\mathrm{a}}$ & Spain $^{\mathrm{a}}$ & Sweden $^{\mathrm{a}}$ \\
\hline Base case & $22,847^{\mathrm{c}}$ & 9,239 & 17,228 & 17,444 & 17,093 & 16,544 & 13,740 & 13,920 & 12,027 & 23,657 \\
\hline \multicolumn{11}{|c|}{ 1-way sensitivity analyses } \\
\hline \multicolumn{11}{|c|}{ Incidence } \\
\hline $30 / 100,000$ & 26,723 & 23,090 & 17,541 & 13,957 & 30,638 & 29,553 & 26,031 & 12,911 & 27,890 & 22,907 \\
\hline $40 / 100,000$ & 18,819 & 16,425 & 11,347 & 9,506 & 22,172 & 21,422 & 18,612 & 9,291 & 20,055 & 15,521 \\
\hline $50 / 100,000 \mathrm{ce}$ & 14,077 & 12,427 & 7,632 & 6,836 & 17,093 & 16,544 & 14,161 & 7,119 & 15,354 & 11,088 \\
\hline \multicolumn{11}{|l|}{ Mortality } \\
\hline $20 \%$ & 17,812 & 9,402 & 15,073 & 18,211 & 17,093 & 16,544 & 11,108 & 21,862 & 8,647 & 11,181 \\
\hline $30 \%$ & 11,875 & 6,268 & 10,050 & 12,142 & 11,395 & 11,029 & 7,406 & 14,574 & 5,765 & 7,454 \\
\hline $40 \%$ & 8,906 & 4,702 & 7,538 & 9,107 & 8,546 & 8,271 & 5,555 & 10,931 & 4,324 & 5,591 \\
\hline $\begin{array}{l}\text { Separate visit } \\
\text { for vaccination }\end{array}$ & 40,478 & 15,445 & 45,912 & 41,399 & 27,734 & 19,218 & 26,068 & 28,230 & 23,803 & 52,004 \\
\hline \multicolumn{11}{|c|}{ Vaccination effectiveness } \\
\hline Best case & 15,020 & 5,512 & 9,556 & 11,123 & 12,480 & 12,052 & 8,749 & 9,218 & 7,498 & 14,330 \\
\hline Worst case & 46,283 & 32,905 & 58,893 & 35,509 & 41,343 & 39,857 & 39,799 & 27,889 & 26,448 & 52,096 \\
\hline \multicolumn{11}{|l|}{ Vaccine price } \\
\hline-3 Euro & 18,832 & 7,299 & 12,837 & 13,568 & 15,071 & 14,513 & 11,108 & 11,220 & 9,394 & 15,046 \\
\hline +3Euro & 26,862 & 11,178 & 21,618 & 21,321 & 19,116 & 18,575 & 16,372 & 16,619 & 14,660 & 32,267 \\
\hline ALOS 10 days & 25,140 & 9,551 & 20,074 & 18,400 & 18,157 & 17,434 & 15,408 & 13,142 & 12,503 & 23,935 \\
\hline $\begin{array}{l}\text { No QALY } \\
\text { adjustment }\end{array}$ & 14,280 & 5,651 & 10,696 & 10,734 & 11,030 & 10,671 & 8,701 & 8,586 & 7,331 & 14,337 \\
\hline \multicolumn{11}{|l|}{ Discount rate } \\
\hline $0 \%$ & 16,076 & 6,219 & 10,350 & 12,145 & 12,230 & 11,823 & 9,090 & 10,250 & 8,422 & 16,337 \\
\hline $5 \%$ & 27,735 & 11,381 & 22,018 & 21,266 & 20,697 & 20,034 & 17,057 & 16,546 & 14,631 & 28,848 \\
\hline \multicolumn{11}{|c|}{ 2-way sensitivity analysis } \\
\hline \multicolumn{11}{|c|}{ Incidence $50 / 100,000$} \\
\hline Mortality $20 \%$ & 10,451 & 11,511 & 6,533 & 6,779 & 17,093 & 16,544 & 11,345 & 10,428 & 9,187 & 4,778 \\
\hline Mortality $30 \%$ & 6,968 & 7,674 & 4,356 & 4,520 & 11,395 & 11,029 & 7,564 & 6,952 & 6,124 & 3,186 \\
\hline Mortality $40 \%$ & 5,226 & 5,755 & 3,268 & 3,390 & 8,546 & 8,271 & 5,673 & 5,214 & 4,593 & 2,390 \\
\hline
\end{tabular}

$A L O S$ average length of stay, $Q A L Y$ quality-adjusted life-year

${ }^{a}$ Reported earlier [13]

${ }^{\mathrm{b}}$ See Appendix for details 


\section{Discussion}

The results of our study for five new countries confirm those obtained for the five countries included in our earlier report [13]. They indicate that pneumococcal vaccination of elderly people to prevent IPD is a cost-effective intervention for each of these 10 Western European countries. Other studies reported from The Netherlands [28], France [29], and England and Wales [25] have reached similar conclusions, as have a report from Canada [30] and an earlier report from the USA [12]. A more recent report from the USA indicates that for preventing IPD alone, extending pneumococcal vaccination to people $\geq 50$ years of age also would be cost-effective [31].

In our base-case analyses, we found threefold differences in the CERs between the 10 countries we studied. The univariate sensitivity analyses showed that these differences reflected different values for the epidemiological and economic variables for each country. For the economic variables, lower CERs were found in Denmark and Scotland, where costs for hospital admissions were low, whereas the reverse was found in England and Wales, where the hospital costs were high. Different vaccine prices had less effect on the CERs, although, as expected, requiring separate visits for pneumococcal and influenza vaccination dramatically increased the CERs in all countries. Evidence from clinical practice, however, indicates that $75-85 \%$ of pneumococcal vaccinations are given during the influenza vaccination season, presumably during the same physician visit [32], and that doing so is safe and does not compromise antibody response to either vaccine [33]. However, economic variables were less important than epidemiological variables in accounting for differences in the CERs between countries.

For the nine countries (excluding Italy) for which we had data, the incidence rates for IPD among elderly persons used in our base-case analyses varied considerably (Table 1). Substantial variations (2- to 3-fold) in the incidence of IPD have been reported between and within developed countries [1]. They are thought to be due primarily to different rates of obtaining blood cultures in people hospitalized with community-acquired pneumonia, as evidenced by reports of steadily increasing rates of pneumococcal bacteremia over time despite constant rates of pneumococcal meningitis [1, 34]. Several studies from the USA, Canada, Australia, and Israel have reported rates of IPD among the elderly of $\geq 50$ / 100,000 [1]. For the six countries in our study that reported lower rates $(\leq 36 / 100,000)$, it is almost certain that the true incidence of IPD was underestimated. After our analyses were completed, a study was published from Italy indicating that in two regions the incidence of IPD among people $\geq 65$ years of age was 5.7 (Piemonte) and 0.2 (Puglia) per 100,000 [35]. These rates are uniquely lower than those reported in all other developed countries and strongly suggest a serious degree of underreporting. For this reason, we believe it was reasonable to assume an incidence of 50/ 100,000 for elderly people in Italy.

We obtained epidemiological data on IPD mortality rates for people $\geq 65$ years of age for only 4 of the 10 countries, and had to use rates for all-cause pneumonia or estimates $(20 \%)$ for the other 6 (Table 1). In five of the countries, the mortality rates we used were $<20 \%$, rates considerably lower than those reported in epidemiological studies from several European countries (France 28\%, The Netherlands $31 \%$, Scotland 43\%, Spain 24\%, and Sweden 33\%) [1]. Moreover, in published case series, IPD mortality rates among the elderly have ranged from 18 to $51 \%$, but in almost all instances they have been above $20 \%$ and, in many instances, above 30\% [1]. In two recent reports of pneumococcal bacteremia in elderly people, the 28 - to 30 -day mortality rate in both studies was $22 \%[36,37$; Y. L. Yu, personal communication]. These findings indicate that for the countries for which we used base-case mortality rates of $<20 \%$, we probably underestimated the true impact of IPD mortality.

Because the incidence and mortality rates used in the most of the base-case analyses were lower than those reported in more reliable empirical studies, the CERs we obtained for these countries most likely underestimate the cost-effectiveness of pneumococcal vaccination. When more plausible assumptions for incidence $(50 / 100,000)$ and mortality $(20 \%, 30 \%$, or $40 \%)$ were used in the twoway sensitivity analyses, the CERs changed substantially. For example, in the base-case analysis for Sweden, where we used an incidence of 34/100,000 and a mortality of $12 \%$, the resulting CER was $€ 23,657$, but in the two-way sensitivity analysis it fell to $€ 4,778$ (mortality $20 \%$ ). For France, increasing the incidence from 29.3 to $50 / 100,000$ led to a decrease in the CERs from $€ 17,444$ to $€ 6,534$ (mortality $20 \%$ ) and $€ 4,357$ (mortality $30 \%$ ). (The mortality in the base-case analysis for France was 25.8\%.) For The Netherlands, increasing the base-case mortality rate (16.1\%) decreased the CERs to $€ 11,345$ (mortality 20\%) or $€ 7,564$ (mortality 30\%). The base-case analyses for Germany and Italy assumed an incidence of 50/100,000 and a mortality of $20 \%$, but increasing mortality to $30 \%$ reduced the CERs to approximately $€ 11,000$. For Denmark, the two-way sensitivity analysis had little effect on the CERs because the values for incidence and mortality were similar to those used for the base-case analysis.

Our results were similar to those obtained in other costeffectiveness studies. Dutch investigators used epidemiological and economic variables similar to ours, and all CERs in their base-case and univariate analyses were < $€ 16,000$ [28]. French investigators also used epidemiological and economic variables similar to ours, but the results 
of their study cannot be compared with ours because their CERs were expressed in terms of saving one more life instead of life-years gained (LYG) or QALYs [29]. In a cost-effectiveness study reported for England and Wales [25], the investigators obtained a CER of $€ 13,761$ per LYG (base-case analysis, $£ 9,477 ; £ 1.00=€ 0.62$ ), a value lower than our CER of $€ 17,228$. Their study differed from ours in several ways. For vaccine efficacy, they used estimates of $20 \%$ for high-risk individuals ( $10 \%$ of all subjects) and $65 \%$ for non-high-risk subjects and assumed that protection was constant over 5- to 6.5-year periods. These estimates are at odds with those used in other cost-effectiveness studies $[12,13,28,29]$ and fail to reflect the well-known decline in clinical protection and antibody levels that occur over the 5-year period following vaccination $[1,5]$. The investigators also assumed that every patient with IPD would receive antibiotic treatment before hospital admission, an assumption that for community-acquired pneumonia ( $\sim 90 \%$ of cases of IPD are bacteremic pneumonia) is not supported by empirical evidence [1]. Their cost estimates for an episode of hospital care and vaccination were lower than ours, and they reported their results as CERs per LYG, not QALYs. Each of their assumptions would have given lower CERs than were obtained with our assumptions. Nonetheless, in both their base-case analysis and ours, pneumococcal vaccination was found to be costeffective. Moreover, when we used a more plausible incidence of IPD of 50/100,000 and a mortality of $20 \%$ (they used 18\%), the CER for England and Wales decreased to $€ 6,633$ per QALY despite our more conservative assumptions for several important variables. A more recent study examined the cost-effectiveness of pneumococcal vaccination from the perspective of a developed country and assumed an effectiveness of 50\% against both IPD morbidity and mortality [38]. For elderly people, the net cost to society was $£ 2,500$ per year of life saved.

Our study has several potential limitations, most of which reflect uncertainty about some of the variables. Our estimates of hospital costs were conservative and, we believe, reliable, but our estimates for the incidence and mortality of IPD were more uncertain. In all instances, however, the available data tended to underestimate rather than overestimate these parameters, and we compensated for this in our two-way sensitivity analyses. We used data from one observational study as the source of our estimates of vaccination effectiveness [5], but many observers discount or ignore such findings [14-19, 38]. However, there are good reasons to accept these data $[1,2]$, and they have the advantage of reflecting vaccination effectiveness in the real world rather than vaccine efficacy as determined under the controlled conditions of a clinical trial. We did not consider indirect costs, although to some extent they are implicit in our adjustments for quality of life, nor did we consider unrelated future medical care costs, although some experts believe they should be included [11]. We estimated the health gains from vaccination on the basis of average life expectancy, knowing that because people more likely to develop IPD might have lower-than-average life expectancy, we might have overestimated the cost-effectiveness of vaccination [11]. However, we excluded all costs for outpatient care, ICU care, and hospitalization for nonbacteremic pneumococcal pneumonia; including any one of these variables would have improved the CERs [39]. Several recent reports have shown that among patients hospitalized with community-acquired pneumonia, previous pneumococcal vaccination was associated with a lower incidence of pneumococcal bacteremia [40], fewer complications and shorter hospital stays [40,41], and lower rates of pneumonia mortality [42] and all-cause mortality [41]. One report even suggested that pneumococcal vaccination significantly reduced hospitalization for communityacquired pneumonia by $26 \%$ [42]. These findings provide further evidence that the cost-effectiveness estimates we obtained were conservative and that they can serve as a guide to policy-makers in the countries included in our analysis.

We emphasize that our findings are based on countryspecific economic and, in most cases, epidemiological data. Each country has its own healthcare system and healthcare financing system, and this will affect the results of any costeffectiveness analysis. For this reason, attempts to generalize our findings to other countries in Western Europe should proceed cautiously.

Although several studies of the cost-effectiveness of pneumococcal vaccination have been published, there is little evidence that they have had an effect on policy decisions, a finding that is true of most cost-effectiveness studies [43]. The increase in pneumococcal vaccination that began in several Western European countries in the mid1990s occurred in the absence of country-specific evidence that vaccination would be cost-effective [1]. In several of these countries, there still are no data on the incidence of IPD [1], and in many countries uncertainty about vaccination effectiveness still is widespread [14-19, 44]. In addition, there is uncertainty about the marginal health benefits of pneumococcal vaccination above those of influenza vaccination $[44,45]$. Why this is regarded as an important question is unclear, because IPD continues to occur year-round in countries that already have high levels of influenza vaccine use [46]. The clinical trials that have attempted to evaluate the incremental benefit of pneumococcal vaccination in people who have received influenza vaccine have been inadequate and provide no guidance [1, 2]. Nevertheless, there is solid evidence from observational studies that when used together, the clinical and economic benefits of the two vaccines are additive [47, 48]. 
When static models such as ours are used to assess the costeffectiveness of pneumococcal vaccination, they present few methodological problems [49]. However, the introduction of pneumococcal conjugate vaccine for children in the USA has produced a measurable level of herd immunity and has led to a decrease in the incidence of vaccine-type IPD in older adults [50]. Thus, more dynamic models may be required for future cost-effectiveness analyses in countries where both the polysaccharide and conjugate vaccines are used [49]. For now, however, when only the polysaccharide vaccine is being used in most Western European countries, there is compelling evidence for its clinical effectiveness and costeffectiveness in elderly people. This evidence more than justifies its widespread use.

Acknowledgements The authors gratefully acknowledge the contributions of R. Baltussen, P. Christie, D. de Graeve, G. Duru, J. Gaillat, B. Jonsson, A. Ortqvist, C. Rigaud-Bully, A. Salazar Cifre, and J. Verhagen to the cost-effectiveness study for the first five countries [12]. We thank J. van Emmerik for assistance in developing the cohort model, E. Brounts and M. Hübben for the literature review, and Nathalie Largeron for assistance with the current study. Our work was made possible by an unrestricted grant from Aventis Pasteur MSD (now Sanofi Pasteur MSD).

\section{Appendix}

Table 5 Sources of country-specific data for the five additional countries included in the present study (see earlier report for sources of data for Belgium, France, Scotland, Spain, and Sweden [ 13])

\begin{tabular}{|c|c|}
\hline Country & Data \\
\hline \multicolumn{2}{|c|}{ Incidence of IPD } \\
\hline Denmark & Statens Serum Institut for 1999 \\
\hline England & $\begin{array}{l}\text { Input data from Melegaro and Edmunds }[25] \text {; } \\
\text { constructed weighted average for all age groups }\end{array}$ \\
\hline Germany & $\begin{array}{l}\text { Incidence of IPD in North-Rhine Westphalia in } \\
\text { 2001-2003. Reinert [26] }\end{array}$ \\
\hline Italy & $\begin{array}{l}\text { Plausible figures based on literature review by } \\
\text { Fedson and Musher [1] }\end{array}$ \\
\hline The & Ongoing surveillance of routine isolates in regional \\
\hline Netherlands & $\begin{array}{l}\text { healthcare laboratories; unpublished data of H. de } \\
\text { Neeling, National Institute of Public Health } \\
\text { Department for Health Service Research }\end{array}$ \\
\hline \multicolumn{2}{|c|}{ Mortality rate of IPD } \\
\hline Denmark & $\begin{array}{l}\text { National Board of Health's National Patient Register } \\
\text { (Lands-patientregistret). Diagnosis codes: G001 and } \\
\text { A403 for } 1999\end{array}$ \\
\hline England & $\begin{array}{l}\text { Input data from Melegaro and Edmunds }[25] \\
\text { constructed weighted average for all age groups }\end{array}$ \\
\hline Germany & $\begin{array}{l}\text { Plausible figures based on literature review by Fedson } \\
\text { and Musher [1] }\end{array}$ \\
\hline Italy & $\begin{array}{l}\text { Plausible figures based on literature review by Fedson } \\
\text { and Musher [1] }\end{array}$ \\
\hline $\begin{array}{l}\text { The } \\
\text { Netherlands }\end{array}$ & $\begin{array}{l}\text { Data for pneumococcal pneumonia were used as proxy } \\
\text { (National Hospital Registration, ICD-9 code } 480-486 \text { ) }\end{array}$ \\
\hline
\end{tabular}

Table 5 (continued)

\begin{tabular}{|c|c|}
\hline Country & Data \\
\hline \multicolumn{2}{|l|}{ ALOS for IPD } \\
\hline Denmark & $\begin{array}{l}\text { National Board of Health's National Patient Register } \\
\text { (Lands-patientregistret). Diagnosis codes: G001and } \\
\text { A403 for } 1999\end{array}$ \\
\hline England & $\begin{array}{l}\text { Input data from Melegaro and Edmunds [25]; } \\
\text { constructed weighted average for all age groups }\end{array}$ \\
\hline Germany & $\begin{array}{l}\text { Data for pneumococcal pneumonia were used as proxy } \\
\text { (Federal Health Monitoring System, Germany) }\end{array}$ \\
\hline Italy & $\begin{array}{l}\text { Data from three hospitals in the Lombardy region, } \\
2001\end{array}$ \\
\hline $\begin{array}{l}\text { The } \\
\text { Netherlands }\end{array}$ & $\begin{array}{l}\text { Data for pneumococcal pneumonia were used as proxy } \\
\text { (National Hospital Registration) }\end{array}$ \\
\hline \multicolumn{2}{|l|}{ GP costs } \\
\hline Belgium & $\begin{array}{l}\text { GP fee for each consultation for vaccination, official } \\
\text { tariff, Ministry of Health } 1997\end{array}$ \\
\hline Denmark & $\begin{array}{l}\text { Charge per standard consultation at GP National } \\
\text { Health Insurance Service }\end{array}$ \\
\hline England & $\begin{array}{l}\text { Figure for } 1999 / 2000 \text { Office of Health Economics, } \\
\text { Compendium for Health Statistics } 2000(\mathrm{GP} \text { costs }= \\
14 \text { British pounds [conversion factor, } 1 \text { euro }=0.62 \\
\text { British pounds]) }\end{array}$ \\
\hline Germany & $\begin{array}{l}\text { Average costs of GP consultation based on data of the } \\
\text { Regional Association of SHI-physicians for Westfalen }\end{array}$ \\
\hline Italy & $\begin{array}{l}\text { Average costs per vaccination by GP Ministry of } \\
\text { Health }\end{array}$ \\
\hline The & Average costs for GP consultation according to the \\
\hline Netherlands & $\begin{array}{l}\text { Dutch guidelines, Oostenbrink, et al } 2000 \text {, } \\
\text { Handleiding voor kostenonderzoek. Amstelveen: } \\
\text { College voor Zorgverzekeringen. }\end{array}$ \\
\hline \multicolumn{2}{|c|}{ Hospital care costs } \\
\hline Denmark & $\begin{array}{l}\text { Cost per day in DRG charge, calculated from the DRG } \\
\text { charge for pneumonia and pleurisy (DRG 90) in1999, } \\
\text { Ministry of Health, DRG catalogue, } 2000\end{array}$ \\
\hline England & $\begin{array}{l}\text { Chartered Institute for Public Finance and Accounting } \\
\text { (CIPFA) Health Database Average costs for infectious } \\
\text { disease (costs }=341 \text { British pounds [conversion } \\
\text { factor, } 1 \text { euro }=0.62 \text { British pounds]) }\end{array}$ \\
\hline Germany & $\begin{array}{l}\text { Cost of } 1 \text { hospital day acute care, Federal Health } \\
\text { Monitoring System, Germany }\end{array}$ \\
\hline Italy & $\begin{array}{l}\text { Average cost per hospital day in Italy based on DRG } \\
(089,090,091) \text { Ministry of Health }\end{array}$ \\
\hline $\begin{array}{l}\text { The } \\
\text { Netherlands }\end{array}$ & $\begin{array}{l}\text { Real costs per hospital day based on the calculation of } \\
\text { the University Hospital Maastricht, unpublished data, } \\
\text { T. van Asselt }\end{array}$ \\
\hline
\end{tabular}

$I P D$ invasive pneumococcal disease, ALOS average length of stay, $D R G$ diagnosis-related groups

\section{References}

1. Fedson DS, Musher DM (2004) Pneumococcal polysaccharide vaccine. In: Plotkin SA, Orenstein WA (eds) Vaccines. Saunders, Philadelphia, pp 529-588

2. Fedson DS, Liss C (2004) Precise answers to the wrong question: prospective clinical trials and the meta-analyses of pneumococcal vaccine in elderly and high-risk adults. Vaccine 22:927-946 
3. Shapiro ED, Clemens JD (1984) A controlled evaluation of the protective efficacy of pneumococcal vaccine for patients at high risk of serious pneumococcal infections. Ann Intern Med 101:325-330

4. Sims RV, Steinmann WC, McConville JH, King LR, Zwick WC, Schwartz JS (1988) The clinical effectiveness of pneumococcal vaccine in the elderly. Ann Intern Med 108:653-657

5. Shapiro ED, Berg AT, Austrian R, Schroeder D, Parcells V, Margolis A, Adair RK, Clemens JD (1991) The protective efficacy of polyvalent pneumococcal polysaccharide vaccine. $\mathrm{N}$ Engl J Med 325:1453-1460

6. Butler JC, Breiman RF, Campbell JF, Lipman HB, Broome CV, Facklam RR (1993) Pneumococcal polysaccharide vaccine efficacy. An evaluation of current recommendations. JAMA 270:1826-1831

7. Farr BM, Johnston BL, Cobb DK, Fisch MJ, Germanson TP, Adal KA, Anglim AM (1995) Preventing pneumococcal bacteremia in patients at risk. Results of a matched case-control study. Arch Intern Med 155:2336-2340

8. Jackson LA, Neuzil KM, Yu O, Benson P, Barlow WE, Adams AL, Hanson CA, Mahoney LD, Shay DK, Thompson WW, and the Vaccine Safety Datalink (2003) Effectiveness of pneumococcal polysaccharide vaccine in older adults. $\mathrm{N}$ Engl $\mathrm{J}$ Med 348:1747-1755

9. Dominguez A, Salleras L, Fedson DS, Izquierdo C, Ruiz L, Ciruela P, Fenoll A, Casal J (2005) Effectiveness of pneumococcal vaccination for elderly people in Catalonia, Spain: a case-control study. Clin Infect Dis 40:1250-1257

10. Fedson DS (1998) Pneumococcal vaccination in the United States and 20 other developed countries, 1981-1996. Clin Infect Dis 26:1117-1123

11. Beutels P, Postma MJ (2001) Economic evaluations of adult pneumococcal vaccination strategies. Expert Rev Pharmacoeconomics Outcomes Res 1:47-58

12. Sisk JE, Moskowitz AJ, Whang W, Lin JD, Fedson DS, McBean AM, Plouffe JF, Cetron MS, Butler JC (1997) Cost-effectiveness of vaccination against pneumococcal bacteremia among elderly people. JAMA 278:1333-1339

13. Ament A, Baltussen R, Duru G, Rigaud-Bully C, de Graeve D, Ortqvist A, Jonsson B, Verhaegen J, Gaillat J, Christie P, Cifre AS, Vivas D, Loiseau C, Fedson DS (2000) Cost-effectiveness of pneumococcal vaccination of older people: a study in 5 western European countries. Clin Infect Dis 31:444-450

14. Hirschmann JV, Lipsky BA (1994) The pneumococcal vaccine after 15 years of use. Arch Intern Med 154:373-377

15. Hak E, Grobbee DE, van Essen GA, Buskens E, Verheij TJ (2000) Pneumococcal vaccination of the elderly: do we need another trial? Arch Intern Med 160:1698-1699

16. Moeller K, Kronberg G, Dirksen A (2001) Is polysaccharide pneumococcal vaccine effective in adults? (Danish) Ugeskr Laeger 163:6112-6117

17. Jefferson TO, Demichelli V (2002) Polysaccharide pneumococcal vaccines. BMJ 235:292-293

18. Mangtani P, Cutts F, Hall AJ (2003) Efficacy of polysaccharide pneumococcal vaccine in adults in more developed countries: the state of the evidence. Lancet Infect Dis 3:71-78

19. Jonkers RE, Boersma WG (2003) Pneumococcal vaccination in adults (Dutch). Ned Tijdschr Geneeskd 147:425-428

20. Baltussen RPMH, Ament AJHA, Leidl RM, van Furth R (1997) Cost-effectiveness of vaccination against pneumococcal pneumonia in The Netherlands. Eur J Public Health 7:153-161

21. Weinstein MC, Siegel JE, Gold MR, Kamlet MS, Russell LB (1996) Recommendations of the panel on cost-effectiveness in health and medicine. JAMA 276:1253-1258

22. Moskowitz AJ, Dunn VH, Lau J, Pauker SG (1984) Can "hypersimplified" decision trees be used instead of Markov models? Med Decis Making 4:530
23. Detsky AS, Naglie G, Krahn MD, Naimark D, Redelmeier DA (1997) Primer on medical decision analysis: Part 1-getting started. Med Decis Making 17:123-125

24. Erikson P, Wilson R, Shannon I (1995) Years of healthy life. Healthy people 2000. Stat Notes no. 7. DHHS publication no. (PHS) 95-1237 4-1484. National Center for Health Statistics, Hyattsville, MD, pp 1-15

25. Melegaro A, Edmunds WJ (2004) The 23-valent pneumococcal polysaccharide vaccine. Part II. A cost-effectiveness analysis for invasive disease in the elderly in England and Wales. Eur J Epidemiol 19:365-375

26. Reinert RR (2005) Invasive pneumococcal disease in adults in North-Rhine Westphalia, Germany, 2001-2003. Clin Microbiol Infect 11:985-991

27. Finkler SA (1982) The distinction between costs and charges. Ann Intern Med 196:102-109

28. Postma MJ, Heijnen M-LA, Jager JC (2001) Cost-effectiveness analysis of pneumococcal vaccination for elderly individuals in The Netherlands. Pharmacoeconomics 19:215-222

29. Amazian K, Nicoloyannis N, Colin C, Nguyen VH, Duru G (2002) Cost-effectiveness analysis of pneumococcal vaccination of older people in France. Med Mal Infect 32:405-417

30. Conseil d'Evaluation des Technologies de la Sante du Quebec (1999) Cost-effectiveness and cost-utility of a pneumococcal immunization program in Quebec. CETS, Montreal, Report no. CETS 98-4RE

31. Sisk JE, Whang W, Butler JC, Sneller V-P, Whitney CG (2003) Cost-effectiveness of vaccination against invasive pneumococcal disease among people 50 through 64 years of age: role of comorbid conditions and race. Ann Intern Med 138:960-968

32. Peetermans WE, Lacante P (1999) Pneumococcal vaccination by general practitioners: an evaluation of current practice. Vaccine 18:612-617

33. Fletcher TJ, Tunnicliffe WS, Hammond K (1997) Simultaneous immunisation with influenza vaccine and pneumococcal polysaccharide vaccine in patients with chronic respiratory disease. BMJ 314:1663-1665

34. Yu VL, Chiou CC, Feldman C, Ortqvist A, Rello J, Morris AJ, Baddour LM, Luna CM, Snydman DR, Ip M, Ko WC, Chedid $\mathrm{MB}$, Andremont A, Klugman KP, and the International Pneumococcal Study Group (2003) An international prospective study of pneumococcal bacteremia: correlation with in vitro resistance, antibiotics administered, and clinical outcome. Clin Infect Dis $37: 230-237$

35. D'Ancona F, Salmaso S, Barale A, Boccia D, Lopalco PL, Rizzo C, Monaco M, Massari M, Demicheli V, Pantosti A, and the Italian PNC-Euro Working Group (2005) Incidence of vaccine preventable pneumococcal invasive infections and blood culture practices in Italy. Vaccine 23:2494-2500

36. Lujan M, Gallego M, Fontanals D, Mariscal D, Rello J (2004) Prospective observational study of bacteremic pneumococcal pneumonia: effect of discordant therapy on mortality. Crit Care Med 32:625-631

37. Sleeman K, Knox K, George R, Miller E, Waight P, Griffiths D, Efstratiou A, Broughton K, Mayon-White RT, Moxon ER, Crook DW, Public Health Laboratory Service, and the Oxford Pneumococcal Surveillance Group (2001) Invasive pneumococcal disease in England and Wales: vaccination implications. J Infect Dis 183:239-246

38. Mangtani P, Roberts JA, Hall AJ, Cutts FT (2005) An economic analysis of a pneumococcal vaccine programme in people aged over 64 years in a developed country setting. Int J Epidemiol 34:565-574

39. Ament A, Fedson DS, Christie P (2001) Pneumococcal vaccination and pneumonia; even a low level of clinical effectiveness is highly cost-effective. Clin Infect Dis 33:2078-2079 
40. Mykietiuk A, Carratala J, Dominguez A, Manzur A, FernandezSabe N, Dorca J, Tubau F, Manresa F, Gudiol F (2006) Effect of prior pneumococcal vaccination on clinical outcome of hospitalized adults with community-acquired pneumococcal pneumonia. Eur J Clin Microbiol Infect Dis 25:457-562

41. Fisman DN, Abrutyn E, Spaude KA, Kim A, Kirchner C, Daley J (2006) Prior pneumococcal vaccination is associated with reduced death, complications and length of stay among hospitalized adults with community-acquired pneumonia. Clin Infect Dis 42:1093-1101

42. Vila-Corcoles A, Ochoa-Gondar O, Hospital I, Ansa X, Vilanova A, Rodriguez T, Llor C, and the EVAN Study Group (2006) Protective effects of the 23-valent pneumococcal polysaccharide vaccine in the elderly population: the EVAN-65 study. Clin Infect Dis $43: 860-868$

43. Oliver A, Mossialos E, Robinson R (2004) Health technology assessment and its influence on health-care priority setting. Int $\mathrm{J}$ Technol Assess Health Care 20:1-10

44. Kullberg BJ (2004) Vaccination against pneumococcal infections in elderly persons and immunocompromised adults. Dutch Health Council. (Dutch). Ned Tijdschr Geneeskd 149:871-874

45. Assendelft WJ, Scholten RJ, Offringa M (2004) Pneumococcal vaccination for the elderly in The Netherlands? Assessment of the quality and content of available comparative studies. Neth J Med 62:36-44

46. The macroepidemiology of influenza vaccination (MIV) study group (2005) The macroepidemiology of influenza vaccination in 56 countries, 1997-2003 Vaccine 23:5133-5143

47. Nichol KL, Baken L, Wuorenma J, Nelson A (1999) The health and economic benefits associated with pneumococcal vaccination of elderly persons with chronic lung disease. Arch Intern Med 159:2437-2442

48. Kelly H, Attia J, Andrews R, Heller RF (2004) The number needed to vaccinate $(\mathrm{NNV})$ and population extensions of the NNV: comparison of influenza and pneumococcal vaccine programmes for people aged 65 years and over. Vaccine 22:2192-2198

49. Beutels P, van Doorslaer E, van Damme P, Hall J (2003) Methodological issues and new developments in the economic evaluation of vaccines. Exp Rev Vaccines 2:949-960

50. Lexau CA, Lynfield R, Danila R, Pilishvili T, Facklam R, Farley MM, Harrison LH, Schaffner W, Reingold A, Bennett NM, Hadler J, Cieslak PR, Whitney CG, and the Active Bacterial Core Surveillance Team (2005) Changing epidemiology of invasive pneumococcal disease among older adults in the era of pediatric pneumococcal conjugate vaccine. JAMA 294:2043-2051 